\title{
A Model of Foam Density Prediction for Expanded Perlite Composites
}

\author{
Md Arifuzzaman ${ }^{a}$, Ho Sung Kim ${ }^{b}$ \\ Mechanical Engineering, School of Engineering, Faculty of Engineering and Built Environment, The University of Newcastle, Callaghan, \\ NSW 2308, Australia
}

\begin{abstract}
Multiple sets of variables associated with expanded perlite particle consolidation in foam manufacturing were analyzed to develop a model for predicting perlite foam density. The consolidation of perlite particles based on the flotation method and compaction involves numerous variables leading to the final perlite foam density. The variables include binder content, compaction ratio, perlite particle size, various perlite particle densities and porosities, and various volumes of perlite at different stages of process. The developed model was found to be useful not only for prediction of foam density but also for optimization between compaction ratio and binder content to achieve a desired density. Experimental verification was conducted using a range of foam densities $\left(0.15-0.5 \mathrm{~g} / \mathrm{cm}^{3}\right)$ produced with a range of compaction ratios $(1.5-3.5)$, a range of sodium silicate contents $(0.05-0.35 \mathrm{~g} / \mathrm{ml})$ in dilution, a range of expanded perlite particle sizes (1 - $4 \mathrm{~mm}$ ), and various perlite densities (such as skeletal, material, bulk, and envelope densities). A close agreement between predictions and experimental results was found.
\end{abstract}

\section{Introduction}

Perlite is a glassy volcanic rock of rhyolitic composition [1], which can be processed into an expanded form for cellular structure formation $[2,3]$. The expansion takes place due to the presence of water in perlite when heated to about $649-816^{\circ} \mathrm{C}$ [4]. The expanded perlite particles are light, environment-friendly [5], and possess good acoustic [6] and insulation properties [7]. Their uses are broadly covered in the literature by Kendall [8]. They have been used as additives ora main constituent for composites. However, their applications as the main constituent of composites have been limited due to relatively poor mechanical properties when manufactured with the conventional manufacturing methods. Recently Kim [9] and Shastri [10] studied some selected properties for mechanical behavior of perlite foam consolidated with starch for demonstration of a new manufacturing process based on the principle of flotation [11-16]. The new process appears to be capable of extending the limitation of perlite application, allowing us to manufacture samples for exploring novel mechanical behavior of consolidated expanded perlite particles. However, controlling of foam density has been a subject due to the complexity involving a variable perlite foam density at different manufacturing stages and other multiple variables such as binder content and compaction ratio.

In this work, a predictive model for perlite foam density was developed as part of optimization of the manufacturing process. The model is verified against the experimental results obtained from perlite/sodium silicate foam manufactured using the method developed by Shastri and Kim [10].

\section{Manufacturing processes}

Manufacturing process of perlite foam includes binder dilution, mixing of perlite and binder, compaction, and drying. The basic principle for manufacturing is based on the particle buoyancy as already described elsewhere [10] involving the following sequential steps: (a) dilution of binder without perlite particles; (b) mixing of perlite particles with diluted binder - top phase consists of binder and perlite particles; middle phase consists of diluted binder, and bottom phase consists of perlite fragments (negligible); (c) top phase removal for foam moulding and compaction; (d) wet-mix charging; and (e) compaction.

\section{Theoretical formulation for foam density}

The final manufactured foam density after drying (of) is dependent on multiple variables including binder content, compaction ratio (c) $\left(=\mathrm{v}_{\text {top }} / \mathrm{v}_{\text {topc }}\right)$, perlite particle size, various perlite particle densities and porosities, and various volumes of perlite at different stages of process (see Fig. 1for notation).

The wet density of top phase mixture after compaction $\left(\varrho_{\text {topc }}\right)$ is given by:

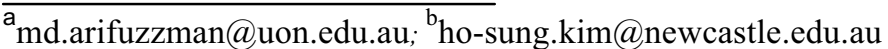




$$
\begin{gathered}
\rho_{\text {topc }=} \mathrm{m}_{\text {topc }} / \mathrm{v}_{\text {topc }}=\mathrm{cm}_{\text {topc }} / \mathrm{v}_{\text {top }}=\mathrm{cm}_{\text {topc }} / \mathrm{nv}_{\mathrm{pB}}= \\
\mathrm{cm}_{\text {topc }} / \mathrm{n}\left(1 / \rho_{\mathrm{pB}}\right)=\mathrm{cm}_{\text {topc }} \rho_{\mathrm{pB}} / \mathrm{n} .
\end{gathered}
$$

where, $n=v_{\text {top }} / v_{\mathrm{pB}}$ (e.g. $\mathrm{n} \approx 1$ in the case of sodium silicate but $n>1$ for starch binder) and $m_{\text {topc }}$ is the top phase mass per unit perlite mass. The $\mathrm{m}_{\text {topc }}$ consists of the individual masses per unit perlite mass:

$$
\begin{aligned}
m_{\text {tope }}=\left(M_{p}+M_{b c}+M_{d c}\right) / M_{p}= \\
1+M_{b c} / M_{p}+M_{d c} / M_{p}
\end{aligned}
$$

Where, $M_{p}, M_{b c}$, and $M_{d c}$ are mass of perlite, mass of binder after compaction, and mass of diluent after compaction respectively in wet foam.
The $\varrho_{f}$ may be obtained from Eq. 1 and Eq. 2 by setting $\mathrm{M}_{\mathrm{dc}}$ to zero:

$$
\rho_{\mathrm{f}}=\mathrm{c} \rho_{\mathrm{pB}}\left(1+\mathrm{R}_{\mathrm{bp}}\right) / \mathrm{n}=\mathrm{c} \rho_{\mathrm{pB}} / \mathrm{nm}_{\mathrm{p}}
$$

where, $\varrho_{\mathrm{pB}}$ is the perlite bulk density, and $\mathrm{R}_{\mathrm{bp}}\left(=\mathrm{M}_{\mathrm{bc}} / \mathrm{M}_{\mathrm{p}}=\mathrm{m}_{\mathrm{bc}} / \mathrm{m}_{\mathrm{p}}=\left(1-\mathrm{m}_{\mathrm{p}}\right) / \mathrm{m}_{\mathrm{p}}=1 / \mathrm{m}_{\mathrm{p}}-1\right)$ is the mass of binder per unit mass of perlite in foam $\left(\mathrm{m}_{\mathrm{bc}}\right.$ and $\mathrm{m}_{\mathrm{p}}$ are mass fractions of binder and perlite in dry foam).

If a unit mass of perlite is mixed with binder and compacted to a volume, $\mathrm{v}_{\mathrm{topc}}$, the total volume $\left(\mathrm{v}_{\mathrm{tvc}}\right)$ after compaction consisting of volumes of inter-particle $\left(\mathrm{v}_{\mathrm{vic}}\right)$, open pores $\left(\mathrm{v}_{\mathrm{voc}}\right)$, and closed pores $\left(\mathrm{v}_{\mathrm{vcc}}\right)$ (see Fig.1) is found as a function of compaction ratio (c) and material properties,

$$
\begin{aligned}
& \mathrm{v}_{\mathrm{tvc}}=\left(\mathrm{v}_{\text {topc }}-\mathrm{v}_{\mathrm{pM}}\right)=\left(\mathrm{v}_{\text {top }} / \mathrm{c}-\mathrm{v}_{\mathrm{pM}}\right)=\left(\mathrm{nv}_{\mathrm{pB}} / \mathrm{c}-\mathrm{v}_{\mathrm{pM}}\right)=\left(\mathrm{n} / \mathrm{c} \rho_{\mathrm{pB}}-1 / \rho_{\mathrm{pM}}\right) \text {. } \\
& \text { Various volumes can be identified as follows: } \\
& \mathrm{v}_{\mathrm{vi}}\left(\mathrm{v}_{\text {top }}-\mathrm{v}_{\mathrm{pE}}\right)=\left(\mathrm{nv}_{\mathrm{pB}}-\mathrm{v}_{\mathrm{pE}}\right)=\left(\mathrm{n} / \rho_{\mathrm{pB}}-1 / \rho_{\mathrm{pE}}\right) \text {, } \\
& \mathrm{v}_{\mathrm{vic}}=\left(\mathrm{v}_{\text {topc }}-\mathrm{v}_{\mathrm{pEc}}\right)=\left(\mathrm{v}_{\mathrm{top}} / \mathrm{c}-\mathrm{v}_{\mathrm{pEc}}\right)=\left(\mathrm{nv}_{\mathrm{pB}} / \mathrm{c}-\mathrm{v}_{\mathrm{pEc}}\right)=\left(\mathrm{n} / \mathrm{c} \rho_{\mathrm{pB}}-1 / \rho_{\mathrm{pEc}}\right) \text {, } \\
& \mathrm{v}_{\mathrm{vo}}=\left(\mathrm{v}_{\mathrm{pE}-} \mathrm{v}_{\mathrm{pS}}\right)=\left(1 / \rho_{\mathrm{pE}}-1 / \rho_{\mathrm{pS}}\right) \text {, } \\
& \mathrm{v}_{\mathrm{voc}}\left(\mathrm{v}_{\mathrm{pE}-} \mathrm{v}_{\mathrm{pSc}}\right)=\left(1 / \rho_{\mathrm{pEc}}-1 / \rho_{\mathrm{pS}}\right) \text {, } \\
& \mathrm{v}_{\mathrm{vc}=}\left(\mathrm{v}_{\mathrm{v}-} \mathrm{v}_{\mathrm{vo}}-\mathrm{v}_{\mathrm{vi}}\right)=\mathrm{v}_{\mathrm{pS}-} \mathrm{v}_{\mathrm{pM}}=\left(1 / \rho_{\mathrm{pS}}-1 / \rho_{\mathrm{pM}}\right) \text {, and } \\
& \mathrm{v}_{\mathrm{vcc}}=\left(\mathrm{v}_{\mathrm{vc}-}-\mathrm{v}_{\mathrm{voc}}-\mathrm{v}_{\mathrm{vic}}\right)=\mathrm{v}_{\mathrm{pSc}-} \mathrm{v}_{\mathrm{pM}}=\left(1 / \rho_{\mathrm{pSc}}-1 / \rho_{\mathrm{pM}}\right)
\end{aligned}
$$

where, $\varrho$ and $\mathrm{v}$ represents density and volume per unit mass of perlite and subscripts vi, vic, vo, voc, vc, $\mathrm{vcc}, \mathrm{pB}, \mathrm{pE}, \mathrm{pS}, \mathrm{pM}, \mathrm{pEc}$, and $\mathrm{pSc}$ stand for interparticle before compaction, inter-particle after compaction, open pores before compaction, open pores after compaction, closed pores before compaction, closed pores after compaction, perlite bulk, envelope, skeletal, material, envelope after compaction, and skeletal after compaction respectively.

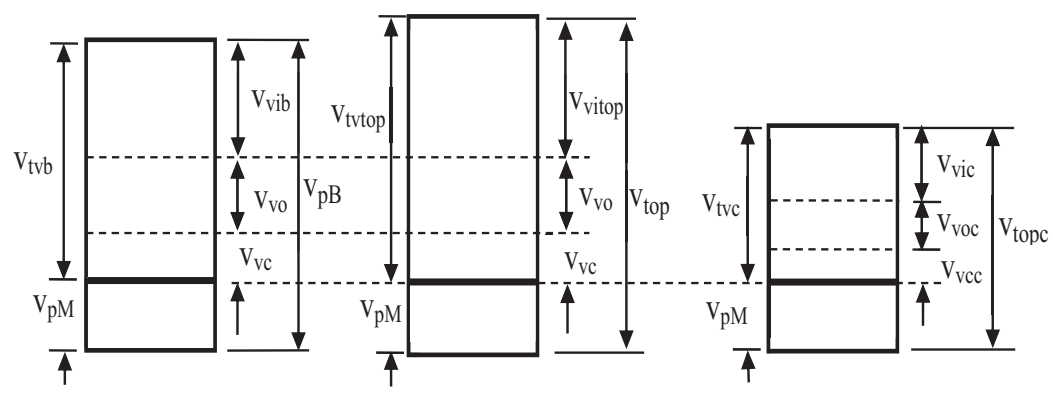

$\begin{array}{lll}\text { (a) Bulk volume stage } & \text { (b) Top phase volume } & \text { (c) After compaction }\end{array}$

Figure 1. Illustration of relative volumes of perlite per unit mass at different stages: (a) bulk volume before compaction without binder; (b) top phase volume before compaction; (c) final volumes after compaction. The symbols $\mathrm{v}_{\mathrm{tvb}}, \mathrm{v}_{\mathrm{tvtop}}$, and $\mathrm{v}_{\mathrm{tvc}}$ denote total volumes excluding $\mathrm{v}_{\mathrm{pM}}$ (material volume). The $\mathrm{v}_{\mathrm{tvb}}$ consists of volumes of inter-particle $\left(\mathrm{v}_{\mathrm{vib}}\right)$, open pores $\left(\mathrm{v}_{\mathrm{vo}}\right)$, and closed pores $\left(\mathrm{v}_{\mathrm{vc}}\right)$. Note that inter-particle volume after compaction $\left(\mathrm{v}_{\mathrm{vic}}\right)<$ inter-particle volumein the top phase $\left(\mathrm{v}_{\mathrm{vitop}}\right), \mathrm{v}_{\mathrm{voc}}>\mathrm{v}_{\mathrm{vo}}$ (up to a point where a particle contains no closed pores - particles are different), $\mathrm{v}_{\mathrm{vcc}}<\mathrm{v}_{\mathrm{vc}}$.

The volume of diluted binder trapped in the compact

$$
\begin{aligned}
& \mathrm{v}_{\mathrm{dbc}}=\mathrm{v}_{\mathrm{vic}}+\mathrm{v}_{\mathrm{voc}}=\left(\mathrm{n} / \mathrm{c} \rho_{\mathrm{pB}}-{ }_{1} / \rho_{\mathrm{pEc}}\right)+\left({ }_{1} / \rho_{\mathrm{pEc}}-{ }_{1} / \rho_{\mathrm{pSc}}\right)= \\
& \left(\mathrm{n} / \mathrm{c} \rho_{\mathrm{pB}}-{ }_{1} / \rho_{\mathrm{pSc}}\right) .
\end{aligned}
$$


Therefore, the total mass of pure binder trapped after compaction $\left(\mathrm{M}_{\mathrm{bc}}\right)$,

$$
\mathrm{M}_{\mathrm{bc}}=\mathrm{v}_{\mathrm{dbc}} \times \mathrm{M}_{\mathrm{p}} \times \mathrm{R}_{\mathrm{bd}} .
$$

Thus, mass ratio of pure binder to perlite in the compact $R_{b p}\left(=M_{b c} / M_{p}=1 / m_{p}-1\right)$ may be related to $\mathrm{R}_{\mathrm{bd}}\left[=\mathrm{M}_{\mathrm{bc}} / \mathrm{v}_{\mathrm{dbc}}\right.$; mass of pure binder $\left(\mathrm{M}_{\mathrm{bc}}\right)$ per unit volume of diluted binder $\left(\mathrm{v}_{\mathrm{dbc}}\right)$,

$$
\mathrm{R}_{\mathrm{bp}}+1=\mathrm{M}_{\mathrm{bc}} / \mathrm{M}_{\mathrm{p}}+1=1 / \mathrm{m}_{\mathrm{p}}=1+\mathrm{R}_{\mathrm{bd}} \times \mathrm{v}_{\mathrm{dbc}} .
$$

Therefore, on the assumption that all the volumes (consisting of inter-particle volume and open pores of particles) are occupied by the diluted binder, the final foam density $\left(\varrho_{f}\right)$ according to Eq. 11 and Eq. 13 becomes:

$$
\begin{aligned}
& \rho_{\mathrm{f}}=\mathrm{c} \rho_{\mathrm{pB}} / \mathrm{nm}_{\mathrm{p}}=\mathrm{c} \rho_{\mathrm{pB}}\left(1+\mathrm{R}_{\mathrm{bd}} \mathrm{v}_{\mathrm{dbc}}\right) / \mathrm{n}= \\
& \mathrm{c} \rho_{\mathrm{pB}}\left\{1+\mathrm{R}_{\mathrm{bd}}\left(\mathrm{n} / \mathrm{c} \rho_{\mathrm{pB}}-{ }_{1} / \rho_{\mathrm{pSc}}\right)\right\} / \mathrm{n} .
\end{aligned}
$$

It is noted that $\varrho_{p S c}=Q_{p S}=Q_{p M}$ is a constant for fully open cell structure. For constant $\varrho_{\mathrm{pB}}$, compaction ratio (c) and $\varrho_{\mathrm{pSc}},(14 \mathrm{a})$ may be rewritten as

$$
\rho_{f}=A+B R_{b d}
$$

Where, $\mathrm{A}\left(=\mathrm{c \varrho}_{\mathrm{pB}} / \mathrm{n}\right)$ and $\mathrm{B}\left\{=\mathrm{A}\left(\mathrm{n} / \mathrm{c}_{\mathrm{pB}}-1 / \varrho_{\mathrm{pSc}}\right)\right\}$ are constants. If inter-particle volume and open pores of particles are not fully filled up with diluted binder during manufacturing, (14a) is modified as

$$
\begin{aligned}
& \rho_{\mathrm{f}}=\frac{1}{\mathrm{n}} \mathrm{c} \rho_{\mathrm{pB}}\left(1+\mathrm{R}_{\mathrm{bd}} \mathrm{Sv} \mathrm{dbc}_{\mathrm{db}}\right)= \\
& \qquad \frac{1}{\mathrm{n}} \mathrm{c} \rho_{\mathrm{pB}}\left\{1+\mathrm{R}_{\mathrm{bd}} \mathrm{S}\left(\mathrm{n} / \mathrm{c} \rho_{\mathrm{pB}}-{ }_{1} / \rho_{\mathrm{pSc}}\right)\right\}
\end{aligned}
$$

with a binder filling factor, $\mathrm{S}$, defined as a fraction of $\mathrm{v}_{\mathrm{dbc}}$ given in

$$
\mathrm{B}=\mathrm{AS}\left(\mathrm{n} / \mathrm{c} \rho_{\mathrm{Bp}}-{ }_{1} / \rho_{\mathrm{pSc}}\right) .
$$

If the filling factor (S) is linearly dependent on compaction ratio (c) as

$$
\mathrm{S}=\mathrm{K}_{1} \mathrm{c}+\mathrm{K}_{2},
$$

Equation $14 \mathrm{c}$ may be rewritten for predicting the compaction ratio effect on the foam density,

$$
\rho_{\mathrm{f}}=\mathrm{Lc}^{2}+\mathrm{Mc}+\mathrm{N}
$$

where $\mathrm{L}=-\varrho_{\mathrm{pB}} \mathrm{R}_{\mathrm{bd}} \mathrm{K}_{1} / \mathrm{n}_{\mathrm{pSc}}$

$\mathrm{M}=\mathrm{Q}_{\mathrm{pB}}\left(1-\mathrm{R}_{\mathrm{bd}} \mathrm{K}_{2} / \mathrm{Q}_{\mathrm{pSc}}\right) / \mathrm{n}+\mathrm{R}_{\mathrm{bd}} \mathrm{K}_{1}, \mathrm{~N}=\mathrm{R}_{\mathrm{bd}} \mathrm{K}_{2}$, and $\mathrm{K}_{1}$, and $\mathrm{K}_{2}$ are experimentally determined.

\section{Experimental details}

\subsection{Constituent Materials}

Commercial grades of expanded perlite particles were obtained from Australian Perlite Pty Limited. Expanded perlite particles were sieved using a vibratory sieve shaker (Analysette 3 SPARTAN) into three different particle size ranges i.e. sizes between 1 and $2 \mathrm{~mm}, 2$ and $2.8 \mathrm{~mm}$, and 2.8 and $4 \mathrm{~mm}$, which will be referred to as Size 1-2, Size 2-3, and Size 3-4 respectively. Four different perlite densities and various types of porosities for various particle sizes are reported in reference [17].Sodium silicate solution (ChemSupply) with a density range of $1.37-1.40 \mathrm{~g} / \mathrm{cm}^{3}$, a solid content range of $37.10-38.00 \%$ (by mass), and a weight ratio of silica to sodium oxide $\left(\mathrm{SiO}_{2} / \mathrm{Na}_{2} \mathrm{O}\right)$ range of 3.16-3.22 was used as binder. The dilution of sodium silicate was made with tap water and $\mathrm{R}_{\mathrm{bd}}$ was calculated using a mass of $\mathrm{SiO}_{2}$ and $\mathrm{Na}_{2} \mathrm{O}$ in a volume consisting of $\mathrm{SiO}_{2}$, $\mathrm{Na}_{2} \mathrm{O}$, and water. The density was measured using a gas pycnometer (AccuPyc 1330) and found to be $2.17 \mathrm{~g} / \mathrm{cm}^{3}$.

\subsection{Test sample preparation}

Diluted sodium silicate binder and perlite were mixed in a cylindrical container by tumbling about 40 times. The wet-mix was poured into a cylindrical mould with a diameter of $35 \mathrm{~mm}$ for compaction at a cross head speed of $10 \mathrm{~mm} / \mathrm{min}$ on a universal testing machine (Simadzu $5000)$. The compaction was conducted in two steps to minimize the density variation - the first stroke was for one half of total compaction stroke and then the second stroke was for the final height after top and bottom of the mould were reversed. The compacted samples were kept at a room temperature range of $20-23{ }^{\circ} \mathrm{C}$ for about 15 minutes after the removal from the compaction mould to remove excess diluted binder on the moulded sample by gravity. After recording the mass, the wet sample was placed into an oven (Labec BTC-9090) for drying at a temperature of $80^{\circ} \mathrm{C}$ for at least 12 hours. The dry samples were used within 3 hours of removal from oven.

\section{Discussion on experimental results and theoretical predictions}

The filling factor, $\mathrm{S}$, for different particle sizes was experimentally determined to verify the linearity given in Eq. 16 as a function of compaction ratio, c, and is shown in Fig. 2. The constants in Eq. 16 and Pearson correlation coefficients (r) are listed in Table 3. The filling factor, $S$, was obtained using a ratio of experimental $\mathrm{v}_{\mathrm{dbc}}[=$ (mass of wet compact-mass of dry compact $) /($ Density of diluted binder $)]$ to theoretical $v_{d b c}$ according to Eq. 11 . 


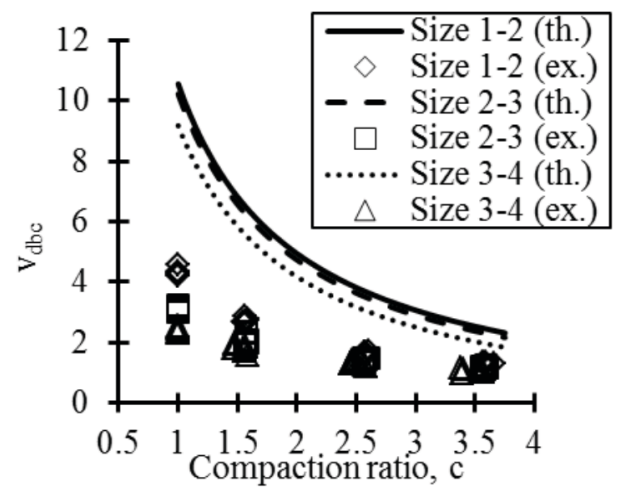

(a)

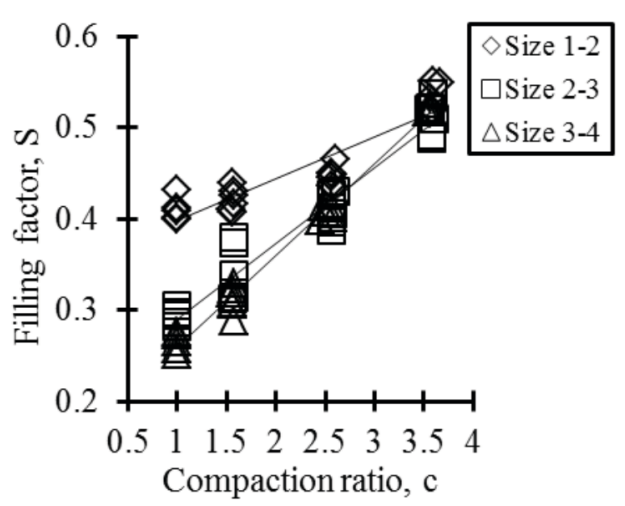

(b)

Figure 2. (a) Volume of diluted binder per unit mass of perlite $\left(\mathrm{v}_{\mathrm{dbc}}\right)$ trapped in the compact versus compaction ratio (c) for various particle Sizes - lines represent values calculated according to Eq. 11. (b) Filling factor as a function of $\mathrm{c}$ irrespective to binder content for various particle Sizes.

It is seen that $\mathrm{S}$ increases with increasing $\mathrm{c}$ as expected, reflecting the fact that unfilled inter-particle volume and open pores of particles reduce during compaction although a small fraction of closed pores in the current work might open and reduce the effect. Also the filling factor, $S$ appears to be affected by particle size at low compaction ratios i.e. the smaller $\mathrm{c}$ the higher $\mathrm{S}$ probably because the capillary action is more active for smaller particles. However, as the compaction ratio increases, such a particle size effect decreases probably due to the fragmentation of particles becoming similar final particle sizes eventually.

Table 3. Constant $\mathrm{K}_{1}$ and $\mathrm{K}_{2}$ (Eq. 16) for various particles size ranges

\begin{tabular}{cccc}
\hline \hline $\begin{array}{c}\text { Perlite } \\
\text { particle } \\
\text { size }\end{array}$ & $\mathrm{K}_{1}$ & $\mathrm{~K}_{2}$ & $\begin{array}{c}\text { Correlation } \\
\text { coefficients (r) }\end{array}$ \\
\hline Size 1-2 & 0.0459 & 0.3515 & 0.919 \\
\hline Size 2-3 & 0.0807 & 0.2145 & 0.968 \\
\hline Size 3-4 & 0.1003 & 0.159 & 0.995 \\
\hline \hline
\end{tabular}

Foam densities measured for particle Size 3-4 with different compact ratios are plotted in Fig. 3(a) as a function of $\mathrm{R}_{\mathrm{bd}}$ in comparison with theoretical predictions. The predictions are based on Eq. $14 \mathrm{c}$ with constants $\mathrm{K}_{1}$ and $\mathrm{K}_{2}$ of Eq. 16 obtained experimentally. As predicted from Eq. 14c, a high linearity for each compaction ratio was obtained as: $y=0.3792 x+0.1345$ with Pearson correlation coefficients $(r)=0.986, y=$ $0.4304 \mathrm{x}+0.2367$ with $\mathrm{r}=0.996$, and $\mathrm{y}=0.4698 \mathrm{x}+$ 0.3361 with $\mathrm{r}=0.999$ for compaction ratios $1.5,2.5$, and 3.5 respectively. The high correlation coefficients indicate that a very close agreement between experiment and prediction.

Foam densities measured for particle Size 3-4 with different $\mathrm{R}_{\mathrm{bd}}$ values are re-plotted in Fig. 3(b) but as a function of $\mathrm{c}$ in comparison with theoretical predictions. The predictions are made according to Eq. 14d with constants $\mathrm{K}_{1}$ and $\mathrm{K}_{2}$ of Eq. 16 obtained experimentally. The following best fit second order polynomial equations with Pearson correlation coefficients (r) are found: $y=-0.0081 x^{2}+0.1419 x-0.043$ with $r=0.999$, $\mathrm{y}=-0.005 \mathrm{x}^{2}+0.1343 \mathrm{x}+0.0149$ with $\mathrm{r}=0.999$, and $\mathrm{y}=$ $-0.01 \mathrm{x}^{2}+0.1659 \mathrm{x}+0.0351$ with $\mathrm{r}=0.997$ for respective binder contents $\left(\mathrm{R}_{\mathrm{bd}}\right), 0.05 \mathrm{~g} / \mathrm{ml}, 0.20 \mathrm{~g} / \mathrm{ml}$, and $0.35 \mathrm{~g} / \mathrm{ml}$. The high correlation coefficients indicate that a very close agreement between experiment and prediction.

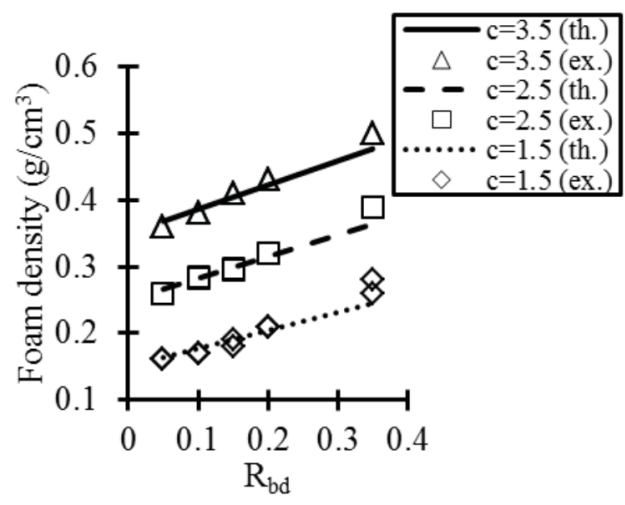

(a)

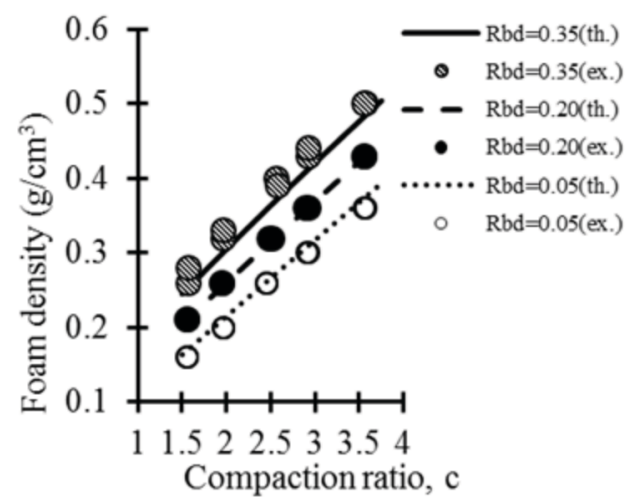

(b)

Figure 3. Foam densities as a function of:(a) pure binder per unit volume of diluted binder $\left(\mathrm{R}_{\mathrm{bd}}\right)$ for various compaction ratios and Size 3-4 with theoretical prediction lines according to Eq. 14b, Eq. 15, and Eq.16; (b) compaction ratio for particle Sze 3-4 with theoretical prediction lines according to Eq. 16 and Eq. 14d. (Constants $\mathrm{K}_{1}$ and $\mathrm{K}_{2}$ of Eq. 16 were found from the least square line of filling factor vs compaction ratio graph (see Fig. 2)). 


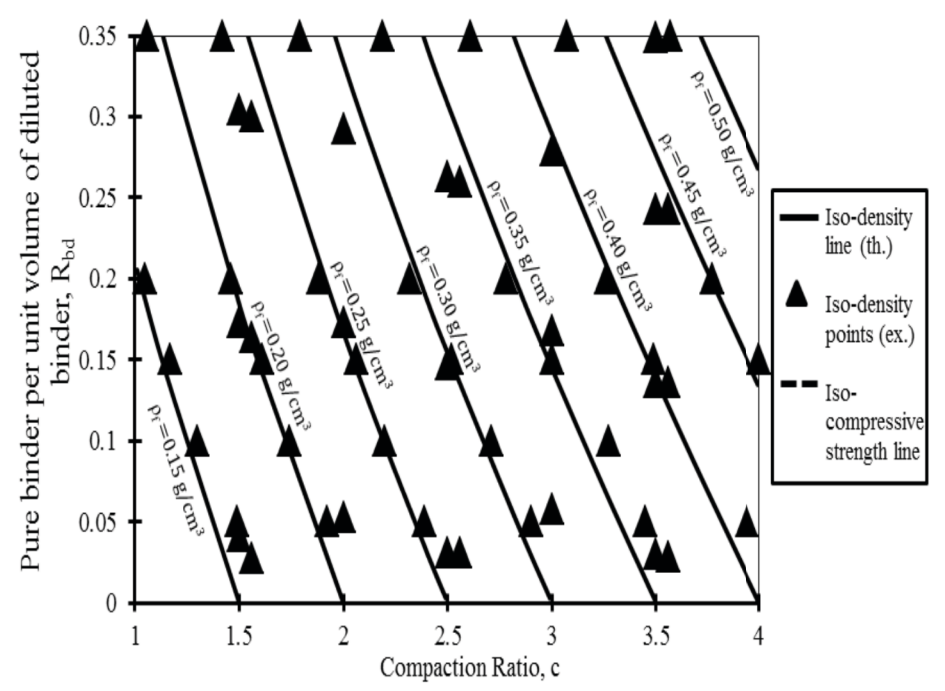

Figure 4. Iso-density curves for perlite foam made of Size 3-4 particles. Solid lines and triangular data points represent theoretical predictions and experiment results respectively. Experimental data points are generated from the least square lines of density vs $\mathrm{R}_{\mathrm{bd}}$ [see Fig. 3(a)] and density vs compaction ratio [see Fig. 3(b)].

Finally, the foam density $\left(\varrho_{f}\right)$ for particle Size $3-4$ is plotted in Fig. 4 as a function of two independent variables (c and $\mathrm{R}_{\mathrm{bd}}$ ) according to $(14 \mathrm{c})$. Each solid line given in Fig. 4 represents an iso-foam density with a calculated value and experimental data points. As expected from earlier regression analysis, a very close agreement between experiment and prediction.

\section{Conclusion}

A model for predicting the perlite/sodium silicate foam density is developed involving various manufacturing variables and material constants. Samples of perlite/sodium silicate foam was manufactured and tested for verification of the model. Foam density was found to linearly vary with binder content and also nonlinearly with compaction ratio. Experimental results were found to be closely predicted by the proposed model.

\section{Acknowledgment}

The authors gratefully acknowledge the Newcastle University International Postgraduate Research Scholarship (NUIPRS) and The University of Newcastle Research Scholarship (UNRSC 50:50) provided for one of authors (MA).

\section{References}

1. R. W. Le Maitre, et al, Igneous rocks: a classification and glossary of terms, recommendations of the international union of geological sciences, Subcommission of the Systematics of Igneous Rocks. 2nd ed., Cambridge University Press, NY, 2002.
2. M. Singh, and M. Garg, Perlite-based building materials - a review of current applications,Construction \& Building Materials,5(1991), 75-81.

3. N. Burriesci, A. Carmelo, P. Antonucci, Physicochemical characterization of perlite of various origins, Materials Letters, 3 (3)(1985), 103-110.

4. S. J. Johnstone, M.G. Johnstone, Minerals for the chemical and allied industries, 2nd ed. Chapman and Hall, London, 1961.

5. J. S. Luongo, U. S. Patent No 6,251,979 B1.(2001)

6. S. Yilmazer, M. B. Ozdeniz, The effect of moisture content on sound absorption of expanded perlite plates,Building and Environment, 40 (2005), 311318.

7. W. P. Dube, L. L. Sparks, A. J. Slifka, Thermal conductivity of evacuated perlite at low temperatures as a function of load and load history, Cryogenics, 31(1991), 3-6.

8. T. Kendall, No sign of the bubble bursting - perlite uses and markets,Industrial Minerals, 2000, 51-59.

9. H. S. Kim, US 2014/0033953 A1. (2014)

10. D. Shastri, H. S. Kim, A new consolidation process for expanded perlite particles, Construction and Building Materials, 60 (2014) 1-7.

11. H. S. Kim, M. M. Islam, Syntactic foams as building materials consisting of inorganic hollow microspheres and starch binder, in: D. C. Cornejo, J. L. Har(Eds.),Building materials: properties and performance and applications. Nova Publishers, 2009. Pp.1-56.

12. H. S. Kim, P. Plubrai, Manufacturing and failure mechanisms of syntactic foam under compression,Composites Part A: Applied Science and Manufacturing, 35 (2004), 1009-1015.

13. M. M. Islam, H. S. Kim, Novel syntactic foams made of ceramic hollow microspheres and starch - 
theory, structure and properties,Journal of Material Science, 42 (2007), 6123-6132.

14. M. M. Islam, H. S. Kim, Manufacture of syntactic foams: pre-mold processing,Materials and Manufacturing Processes, 22 (2007), 28-36.

15. M. M. Islam, H. S. Kim, Manufacture of syntactic foams using starch as binder: post-mold processing,Materials and Manufacturing Processes, 23 (2008), 884-892.

16. M. M. Islam, H. S. Kim, Pre-mould processing technique for syntactic foams: generalised modelling, theory and experiment, Journal of Materials Processing Technology, 211(2011), 708716.

17. M. Arifuzzaman, H.S. Kim, Development of new perlite/sodium silicate composites, International Conference on Mechanical, Industrial and Energy Engineering (ICMIEE),Khulna University of Engineering \& Technology, Khulna, Bangladesh,2014, 26-27. 